\title{
The attitudes of clergy in Benin City, Nigeria towards persons with mental illness
}

\author{
NG Igbinomwanhia, BO James, JO Omoaregba
}

Department of Clinical Services, Federal Psychiatric Hospital, Benin City, Edo State, Nigeria

\begin{abstract}
Objective: The clergy in sub-Saharan Africa play a major role in the care and pathways to orthodox mental health services of the mentally ill. Their attitudes concerning mental illnesses would influence community mental health intervention efforts. This study aimed to determine the attitudes of clergy towards persons with mental illness. Method: A cross-sectional survey of clergy (n= 107) of the Christian and Muslim faiths was conducted, using a socio-demographic questionnaire and the 40- item Community Attitudes towards Mental Illness (CAMI) scale. Results: Stigmatizing attitudes were evident among members of the clergy surveyed. Most (71.1\%) believed the mentally ill were different from other persons, while $68.2 \%$ were of the opinion that the mentally ill should be controlled like children. Over $80 \%$ of respondents were not comfortable with the idea of the mentally ill living in their vicinity and wanted mental health hospitals situated out of residential areas. Almost half of respondents (45.8\%) were uncomfortable with women who were once mentally ill baby-sitting and 63.2\% agreed that our mental hospitals seem more like prisons than where the mentally ill can be cared for. Conclusion: Negative attitudes towards the mentally ill were widespread among the clergy sampled. Mental health professionals need to take proactive steps to improve the mental health knowledge of the clergy which may facilitate their roles in the pathway to mental health care.
\end{abstract}

Keywords: Stigma; Clergy; Attitudes; Mental illness; Nigeria

Received: 11-01-2012

Accepted: 21-05-2012

doi: http://dx.doi.org/10.4314/ajp.sy.v16i3.26

\section{Introduction}

In developing countries the clergy play an important role in the pathways to care of individuals with mentally ill. ${ }^{1-5}$ The clergy are sought by the mentally ill and/or their relatives for diverse reasons and at different stages of the illness. ${ }^{6,7}$ Over half of lay persons surveyed in Nigeria believe that supernatural or spiritual factors cause mental illness. ${ }^{9-11}$ It is unsurprising therefore that in some reports lay persons believe care could best be obtained from nonmedical sources such as the clergy or traditional healers. 3,12 Although attempts to seek help from the clergy may be beneficial, it could actually result in a delay

\section{Correspondence}

Dr BO James

Department of Clinical Services, Federal Psychiatric Hospital,

P.M.B 1108, Benin City, Edo State, Nigeria

email: bawojames@yahoo.com accessing specialised care, consequently worsening treatment outcomes. ${ }^{1,2}$

Public attitudes towards the mentally ill are known to be generally negative. ${ }^{11,16}$ It is also known that knowledge may play a significant role in shaping attitudes which in turn could determine responses to particular situations or circumstances. ${ }^{13}$ What benefit the mentally ill may derive from seeking help from the clergy would therefore be significantly influenced by clergy attitudes, and by the knowledge of the clergy of mental illnesses. Clergy beliefs about mental illness may also be influential in deciding if the patients they come in contact with would eventually be referred to mental health care facilities.

Although studies have established that the clergy form a significant part of the pathway to mental health care in Nigeria little has been done in determining the knowledge of, and attitudes of the clergy to mental illness and psychiatric referrals. Such information could help in determining how best the orthodox mental health care 
system can liaise with this group for the benefit of the mentally ill. We aimed to determine the attitudes of clergy (Christian and Muslim) towards mental illness in Benin City, Nigeria.

\section{Method}

\section{Design and setting}

This cross-sectional prospective study was carried out in Benin City, Edo state, Nigeria. Benin City comprises three local government areas, namely Oredo, Egor, and IkpobaOkha. The study population was sourced from all three local government areas.

\section{Sample size and sampling technique}

At the time of conducting this study, no data was available on the number of clergy within the city.Following a review of the literature on previous studies examining attitudes of clergy toward mental illness, we chose a convenience sample of 200.10,15 This figure we believe adequately covers for non-response and inadequately-filled questionnaires. The number of churches in the three local government areas were subjected to a stratified random sampling procedure with proportionate allocation to each stratum for "category or type of church", e.g. orthodox/ Pentecostal. Participating Pentecostal and syncretic clergymen were reached directly or through the heads of large ministries; orthodox ministers were reached through the heads of dioceses of the Anglican, Catholic, and Baptist denominations. Muslim clerics were reached through two of the largest mosques within the city; a snowballing method was used to reach other Muslim clerics.

\section{Ethics}

The study protocol was reviewed and approved by the Ethics and Research Committee of the Federal Psychiatric Hospital, Uselu, Benin City, Edo State.

\section{Data collection}

Informed consent to conduct the study was obtained from the local branches of the Christian Association of Nigeria, the Pentecostal fellowship of Nigeria, and headquarters of selected churches. Written consent was also obtained from each participating clergyman. Assurance of anonymity was given to each participant. Questionnaires were distributed to ministers at convenient group meetings, e.g. at the monthly diocesan/ ministers conference; or taken by the researcher to clergymen at the offices of sampled churches. Some questionnaires were filled and returned to the researcher immediately, while others were collected at an appointed date. We sent reminders to respondents on 3 separate occasions every fortnight to improve participation rate. A total of 120 questionnaires were retrieved; 13 had over $20 \%$ of incomplete data and were discarded, while 107 were analysed.

\section{Instrument}

Data collection was by a 2-section self-administered questionnaire. Section 1 comprised the sociodemographic characteristics of respondents, including number of years in ministry. Section 2 was the Community
Attitudes towards Mental Illness (CAMI) scale developed by Taylor and Dear. ${ }^{16}$ This instrument comprises 40 items divided into 4 a priori subscales of ten items each viz: Authoritarianism, Benevolence, Social Restrictiveness, and Community Mental Health Ideology. It has been widely used in this environment

\section{Data Analysis}

Data was analysed using the SPSS version 16 statistical software, and results presented in tables.

\section{Results}

\section{Socio-demographic}

The mean age of participants was 43.03(SD=9.97) years, while 12 of the 107 respondents were females (1 1.2\%). All had one form of formal education or the other, ranging from primary (0.9\%) to tertiary (46.7\%) and postgraduate (36.7\%). The majority were Christians of the Pentecostal (53.3\%), orthodox (29.9\%), or syncretic (2.8\%) denomination; 15 (14.0\%) were Muslims. Over two thirds of participants (69.2\%) had not received any form of mental health training. 64 (59.8\%) were willing to provide care for the mentally ill while $23.4 \%$ were unsure (Table I). The absence of data on the number and demography of clerics in Benin-City limits our ability to determine the representativeness of the sample data.

Table I: Socio-demographic characteristics of respondents

\begin{tabular}{|l|c|}
\hline Variable & $N(\%)$ \\
\hline Age : mean (SD) & $43.03(9.97)$ \\
\hline Gender & \\
Male & $95(88.8)$ \\
Female & $12(11.2)$ \\
\hline Level of education & \\
No formal education & $0(0)$ \\
Primary & $1(0.9)$ \\
Secondary & $17(15.9)$ \\
Tertiary & $50(46.7)$ \\
Postgraduate & $39(36.7)$ \\
\hline Faith & \\
Christian (orthodox) & $32(29.9)$ \\
Christian (Pentecostal) & $57(53.3)$ \\
Christian (syncretic) & $3(2.8)$ \\
Islam & $15(14.0)$ \\
\hline Received mental health training? & $74(69.2)$ \\
Yes & $64(59.8)$ \\
No & $18.8)$ \\
\hline Yes & \\
\hline
\end{tabular}

Clergy attitudes towards the mentally ill

Authoritarianism

Clergy attitudes on the authoritarianism scale were largely 
stigmatizing, with $71.1 \%$ of respondents being of the opinion that the mentally ill could easily be differentiated from normal persons ; $68.2 \%$ thought mentally ill persons should be controlled as young children and 58.8\% disagreed with the statement that less emphasis should be placed on protecting the public from the mentally ill (Table II)

\section{Benevolence}

A majority of the clerics interviewed scored high on the benevolence scale. Nevertheless, almost half (46.8\%) disagreed with the statement that our mental hospitals seem more like prisons than where the mentally ill can be cared for (Table III).
Social Restrictiveness

Responses to five of the ten items on the social restrictiveness scale showed that about a third of clergy interviewed considered the mentally ill some form of threat and better avoided (Table IV).

\section{Community Mental Health Ideology}

On the CMHI sub-scale a majority (80.4\%) of the clerics surveyed thought it frightening that mentally ill persons should live in residential neighbourhoods, and most (69.1\%) felt mental health centres should be kept out of residential areas. Almost half of respondents (47.7\%) agreed with the statement that local residents have good reasons to resist the location of a mental hospital in their area (Table V).

\section{Table II: Proportion of respondents positively endorsing statements on the authoritarianism subscale of the CAMI}

\begin{tabular}{|c|c|}
\hline Statements & $N(\%)$ \\
\hline Large mental hospitals are an outdated means of treating the mentally ill (strongly disagree/disagree) & $62(58)$ \\
\hline There is something about the mentally ill that makes it easy to tell them from normal people (strongly agree/agree) & $76(71.1)$ \\
\hline Less emphasis should be placed on protecting the public from the mentally ill (strongly disagree/disagree) & $62(58.8)$ \\
\hline Mental patients need the same kind of control as young children (strongly agree/agree) & $73(68.2)$ \\
\hline A person should be hospitalised once he shows signs of mental illness (strongly agree/agree) & $45(42)$ \\
\hline Mental illness is an illness like any other (strongly disagree/disagree) & $17(15.9)$ \\
\hline Lack of self-discipline and willpower is one of the main causes of mental illness (strongly agree/agree) & $49(45.8)$ \\
\hline Keeping them behind locked doors is one of the best ways to handle the mentally ill (strongly agree/agree) & $26(24.3)$ \\
\hline Virtually any one can become mentally ill (strongly disagree/disagree) & $25(23.3)$ \\
\hline The mentally ill should not be treated as outcasts from society (strongly disagree/disagree) & $8(7.5)$ \\
\hline
\end{tabular}

\begin{tabular}{|c|c|}
\hline Statement & $N(\%)$ \\
\hline The mentally ill are a burden on society (strongly agree/agree) & $40(37.3)$ \\
\hline It is best to avoid anyone who has mental problems (strongly agree/agree) & $25(23.3)$ \\
\hline Our mental hospitals seem more like prisons than like places where the mentally ill can be cared for (strongly agree/agree) & $57(63.2)$ \\
\hline More tax money should be spent on the care and treatment of the mentally ill (strongly disagree/disagree) & $6(5.6)$ \\
\hline The mentally ill do not deserve our sympathy (strongly agree/agree) & $4(3.7)$ \\
\hline The mentally ill have for too long been the subject of ridicule (strongly disagree/disagree) & $14(13)$ \\
\hline We have a responsibility to provide the best care for the mentally ill (strongly disagree/disagree) & $4(3.7)$ \\
\hline We need to adopt a more tolerant attitude towards the mentally ill in our society (strongly disagree/disagree) & $2(1.9)$ \\
\hline Increased spending on mental health services is a waste of tax money (strongly agree/agree) & $5(4.7)$ \\
\hline There are sufficient existing mental health services in Nigeria (strongly agree/agree) & $10(9.4)$ \\
\hline
\end{tabular}


Table IV: Proportion of respondents positively endorsing statements on the social restrictiveness subscale of the CAMI

\begin{tabular}{|c|c|}
\hline Statements & $N(\%)$ \\
\hline The mentally ill should be denied their individual rights (strongly agree/agree) & $7(6.5)$ \\
\hline Women who were once patients in a mental hospital can be trusted as babysitters (strongly disagree/disagree) & $49(45.8)$ \\
\hline The mentally ill should not be given any responsibility (strongly agree/agree) & $37(34.6)$ \\
\hline Anyone with a history of mental illness should be excluded from taking public office (strongly agree/agree) & $27(25.2)$ \\
\hline The mentally ill are far less of a danger than most people suppose (strongly disagree/disagree) & $34(31.8)$ \\
\hline I would not want to live next door to someone who has been mentally ill (strongly agree/agree) & $35(32.7)$ \\
\hline The mentally ill should be isolated from the rest of the community (strongly agree/agree) & $26(24.3)$ \\
\hline No one has the right to exclude the mentally ill from their neighbourhood (strongly disagree/disagree) & $37(34.6)$ \\
\hline Mentally ill patients should be encouraged to assume the responsibility of normal life (strongly disagree/disagree) & $10(9.3)$ \\
\hline A woman would be foolish to marry a man who has suffered from mental illness, though he seems fully recovered (strongly agree/agree) & $20(18.6)$ \\
\hline
\end{tabular}

Table V: Proportion of respondents positively endorsing statements on the community mental health ideology subscale of the CAMI

\begin{tabular}{|c|c|}
\hline Statement & $N(\%)$ \\
\hline Having mental patients living in a residential area might be good therapy, but the risks are too great (strongly agree/agree) & $12(11.2)$ \\
\hline It is frightening to think of people with mental problems living in residential neighbourhoods (strongly agree/agree) & $86(80.4)$ \\
\hline Mental health centres should be kept out of residential areas (strongly agree/agree) & $74(69.1)$ \\
\hline Locating mental health services in residential neighbourhoods does not endanger local residents (strongly disagree/disagree) & $54(50.5)$ \\
\hline Local residents have good reasons to resist the location of a mental hospital in their area (strongly agree/agree) & $51(47.7)$ \\
\hline Residents have nothing to fear from people coming into their area to receive mental health treatment (strongly disagree/disagree) & $37(34.6)$ \\
\hline The best therapy for many mental health problems is to be part of a normal community (strongly disagree/disagree) & $40(37.3)$ \\
\hline As far as possible, mental health services should be provided through community-based facilities (strongly disagree/disagree) & $9(8.4)$ \\
\hline Locating mental health facilities in residential areas downgrades the neighbourhood (strongly agree/agree) & $26(24.3)$ \\
\hline $\begin{array}{l}\text { Residents should accept location of mental health facilities in their neighbourhood to serve the needs of the local community } \\
\text { (strongly disagree/disagree) }\end{array}$ & $21(18.8)$ \\
\hline
\end{tabular}

\section{Discussion}

Negative attitudes towards mentally ill persons have been demonstrated in a number of studies among various occupational groups. ${ }^{10,11,14}$ Such negative attitudes are again reported in this study among clergy. Arguably, clergy are more likely to encounter mentally ill persons in a disturbed state, and are therefore likely to exhibit negative attitudes. ${ }^{16}$ Stigmatizing attitudes are usually reinforced by the belief that the stigmatized group is "different", and in this study over $70 \%$ of respondents believed 'there is something about the mentally ill that makes it easy to differentiate them from normal people'. Furthermore, the negative attitudes may reflect the clergy's lack of understanding of the clinical subtleties of mental illness. Perhaps their viewing severe psychotic mental disorders as the only form of mental illness were reflected in their expressing more stigmatizing attitudes when scenarios describing closer contact with the mentally ill were presented.

Such negative attitudes on the part of the clergy sampled are likely to promote discrimination. The clergy in Benin-City, Nigeria as in most other societies are seen as role models and congregants easily imbibe their views. It is therefore undesirable for clergy to hold stigmatising views about the mentally ill.

Quite significantly, almost half of respondents were of the opinion that mentally ill persons are somehow responsible for 
their illness through a lack of self-discipline and will power. This probably explains why only less than a third disagreed that virtually anyone could become a victim of mental illness. Overall, findings on the authoritarianism scale in this study are suggestive of the fact that clergy perceive mentally ill persons as inferior and requiring coercion and supervision, an opinion frequently held against stigmatized groups. In keeping with the humanistic nature of their profession, respondents in this study showed relatively high scores on the benevolence scale.

While fewer clergy endorsed the statement that persons with mental illness be isolated or prevented from leading a normal life, they nevertheless exhibited a reluctance to entrust certain delicate and sensitive tasks as baby-sitting to persons with a history of mental illness. This perhaps suggests that they covertly view the mentally ill as unpredictable. The high level of social distance associated with a high level of benevolence among the clergy in this study confirms previous reports of the patterns of stigmatising attitudes among lay persons and professionals in Nigeria. ${ }^{18,19}$

There was some reluctance by clergy to accept the provision of mental health services through community-based facilities, with over $80 \%$ of respondents not comfortable with the idea of mentally ill persons living in residential neighbourhoods. Observed negative attitudes by respondents in this study are similar to those expressed by lay persons ${ }^{17}$ and special group. ${ }^{10,11,14}$

\section{Implications for mental healthcare}

Against the backdrop that quite a significant number of mentally ill patients and relatives seek help from clergy ${ }^{1-5}$, these observed negative attitudes by clergy is worrisome. Studies have shown that improved knowledge positively influences attitudes towards mentally ill persons; especially with regards to authoritarianism, discriminatory beliefs, and social integration. ${ }^{13}$ The majority of respondents in this study have not had any form of mental health training. Perhaps deliberate attempts to improve the mental health knowledge of the clergy may facilitate their roles in the pathway to mental health care. Such educational interventions should be conducted with clergy and mental health professionals as collaborators. Efforts are required to identify myths and dispel them, educate the clergy on the common types of mental illness such as depression, acute stress disorders and anxiety and not just psychotic disorders to which they erroneously believe comprise the whole sphere of metal disorders. Specific anti-stigma interventions should also examine the factors that promote social distancing and design strategies to minimise them. In addition, the input of patients (service users) in the anti-stigma program would prove invaluable. Efforts are changing negative attitudes among clergy would have multiplier effects on their congregants in particular and lay persons in general.

\section{Conclusion}

Clergy surveyed in Benin City Nigeria hold negative stigmatising attitudes towards the mentally ill. Further research is warranted to identify the factors that mediate these attitudinal dispositions. The small sample size is a major limitation for this study. We cannot generalize our findings to clergy outside the city, however being one of few reports on this population group, our findings should form a template for future research and educational intervention. Secondly, for the purpose of this study, the absence of a clear operational definition of what constitutes a mental illness may have resulted in biased responses among participants who may mostly view mental illness as comprising entirely of psychotic episodes.

\section{References}

1. Appiah-Poku J, Laugharne R, Mensah E, Osei Y, Burns T. Previous help sought by patients presenting to mental health services in Kumasi, Ghana. Soc Psychiatry Psychiatric Epid 2004; 39: 208-211.

2. Abiodun $O A$. Pathways to mental health care in Nigeria. Psych Services 1995; 46(8) : 823-826.

3. Gureje O, Odejide OA, Acha RA. Pathways to psychiatric care in Ibadan, Nigeria. Trop Geo Med 1995; 47: 125-129.

4. Adeyemi JA, Famuyiwa OO. First ever consultees of a psychiatric out-patient clinic: A pilot study. In 9th Pan-African psychiatric conference report. Edited by Lawal RA. Lagos: Association of Psychiatrists in Nigeria, 1994.

5. Lukoff D, Lu FG, Turner R. Cultural considerations in the assessment and treatment of religious and spiritual problems. Psychiatr Clin North Am 1995; 18: 467.

6. Sadock BJ, Sadock VA. Pastoral counselling. Kaplan and Sadock's synopsis of psychiatry 2003; 9th ed: 899.

7. Gater R, Goldberg DP. Pathways to psychiatric care in south Manchester. Br J Psych 1991; 159: 90-96.

8. Adewuya AO, Makanjuola ROA. Lay beliefs concerning causes of mental illness in Nigeria: pattern and correlates. Soc Psych Psychiatric Epid 2008; 43: 336-341

9. Kabir M, Iliyasu Z, Abubakar IS, Aliyu MH. Perception and beliefs about mental illness among adults in Karfi village, northern Nigeria. BMC Int Health Human Rights 2004; 4:3.

10. Adewuya AO, Oguntade AA. Doctors' attitude towards people with mental illness in western Nigeria. Social Psychiatry Psychiatric Epid 2007; 42: 931-936.

11. Uwakwe R. The views of some selected Nigerians about mental disorders. Niger Postgrad Med J. 2007; 14(4): 31 9-24.

12. Erinosho OA. Pathways to mental health delivery systems in Nigeria. Int J Soc Psych 1977; 23: 55-59.

13. Madianos MG, Priami M, Alevisopoulos G, Koukia E, Rogaku E. Nursing students' attitude change towards mental illness and psychiatric case recognition after a clerkship in psychiatry. Iss Ment Health Nursing 2005; 26(2): 169-183.

14. Aghukwa NC. Secondary school teachers' attitude to mental illness in Ogun state, Nigeria. Afr J Psych 2009; 12:59- 63.

15. Taylor SM, Dear MJ. Scaling community attitudes toward the mentally ill. Schizophrenia Bull 1981; 7:225-240.

16. Psarra V, Sestrini M, Santa Z, Petsas D, Gerontas A, et al. Greek police officers' attitudes towards the mentally ill. Int J Law Psychiatry 2008; 31: 77-85.

17. Gureje O, Lasebikan VO, Ephraim-Oluwanuga O, Olley BO, Kola L. Community study of knowledge of and attitude to mental illness in Nigeria. Br J Psychiatry 2005; 186:436-441

18. Adewuya AO, Makanjuola ROA. Social distance towards people with mental illness in southwestern Nigeria. Aust NZ J Psychiatry 2008; 42:389-395.

19. Abasiubong F, Ekott JU, Bassey EA. A comparative study of attitude to mental illness between journalists and nurses in Uyo, Nigeria. 2007; Afr J Med Med Sci 36:345-351. 